\title{
Ethnic and socio-economic disparities in oral health outcomes and quality of life among Sri Lankan preschoolers: a cross-sectional study
}

\author{
Vajira Nanayakkara ${ }^{1,2^{*}}$, André Renzaho $^{3}$, Brian Oldenburg $^{3}$ and Lilani Ekanayake ${ }^{4}$
}

\begin{abstract}
Introduction: The distribution and severity of dental caries among preschool children vary according to the socio-economic and ethnic differences within and between countries. Understanding socio-economic influences on child oral health could inform early interventions to reduce the oral health burden throughout the life-cycle. The aim of this study is to examine the socio-economic and ethnic influences on oral health among preschoolers in Kegalle, Sri Lanka.
\end{abstract}

Methods: The study involved 784 children aged between 48-72 months recruited from 84 pre-schools in the Kegalle district in Sri Lanka. Cross-sectional data were collected by means of an oral examination of the children and a self-administered questionnaire to their parents/caregivers. The Early Childhood Oral Health Impact Scale (ECOHIS) was used to assess Oral Health related Quality of Life (OHQoL). Univariate and multivariate models of Poisson regression were used to investigate the associations between the variables.

Results: Compared to children whose fathers had tertiary education, those whose fathers did not study beyond grade 5, had more caries measured in terms of decayed, missing and filled surfaces (dmfs) (IRR $=2.30 ; 95 \%$ Cl: 1.30, 4.06; $\mathrm{p}<0.01)$ and experienced poor OHQoL at child (IRR $=2.52 ; 95 \% \mathrm{Cl}: 1.20,5.31 ; \mathrm{p}<0.05)$ and family (IRR $=1.59 ; 95 \% \mathrm{Cl}$ : $1.11,2.27 ; \mathrm{p}<0.05)$ levels. However, lower educational attainment among mothers was associated with better OHQoL among children. Compared to the Sinhalese ethnic group, Tamils had more gingival bleeding (bleeding surfaces) $(\mathrm{IRR}=3.04 ; 95 \% \mathrm{Cl}: 1.92,4.81 ; \mathrm{p}<0.001)$ and poor OHQoL at child level $(\mathrm{IRR}=2.07 ; 95 \% \mathrm{Cl}: 1.19,3.60 ; \mathrm{p}<0.01)$, whereas Muslims had poor OHQoL at family level (IRR $=1.42 ; 95 \% \mathrm{Cl}: 1.10,1.84 ; \mathrm{p}<0.01)$. Children of low-income families had more gum bleeding ( $\mathrm{RR}=1.00 ; 95 \% \mathrm{Cl}: 0.99,1.00 ; \mathrm{p}<0.05$ ) compared to children of high-income families.

Conclusions: Socio-economic and ethnic differences in oral health outcomes exist among this population of preschoolers. Interventions targeting children of fathers with low educational levels and ethnic minority groups are required to reduce inequalities in oral health in Sri Lanka and other similar countries.

Keywords: Oral health, Dental caries, Bleeding gums, Quality of life, Socio-economic disparities, Preschoolers, Sri Lanka

\section{Introduction}

Dental caries and periodontal disease account for a considerable proportion of the global burden of oral diseases [1], thus causing an enormous loss of school and working hours. Research has demonstrated that the oral health of the child makes an important contribution to

\footnotetext{
* Correspondence: vajirananayakkara99@gmail.com

'Global Health and Society Unit, Department of Epidemiology and

Preventive Medicine, Monash University, Level 3, Burnet Building, 89 Commercial Rd, Melbourne, Victoria 3004, Australia

${ }^{2}$ Ministry of Healthcare and Nutrition, Colombo, Sri Lanka

Full list of author information is available at the end of the article
}

the wellbeing of both the child and the family [2]. However, since poor dental behaviours established at preschool age may be difficult to modify, preschool age is a critical period in oral health [3]. Some intervention studies have been carried out to investigate the effectiveness of measures taken to prevent caries in young children. Visiting mothers with infants by trained dental health educators at the time of eruption of first deciduous teeth or soon after was demonstrated to be effective in preventing nursing caries [4]. However, Rayner has shown that preventive programs have only a little effect on the

\section{Biomed Central}

(c) 2013 Nanayakkara et al.; licensee BioMed Central Ltd. This is an open access article distributed under the terms of the Creative Commons Attribution License (http://creativecommons.org/licenses/by/2.0), which permits unrestricted use, distribution, and reproduction in any medium, provided the original work is properly cited. 
uptake of dental care in nursery and young primary school children, although the provision of health education to their parents may be effective in improving the oral hygiene of children [5]. The distribution and severity of oral diseases vary within and between countries depending on socio-economic status and ethnic differences [6-10]. In several Asian and African countries the level of caries is higher in the primary dentition than in the permanent dentition in children [11,12], and poor oral health is unequally distributed in these countries, with those from socially-disadvantaged communities among the most affected [13]. For example, in Sri Lanka, the prevalence of dental caries in primary dentition of 5 years old children is $65 \%$ [12], while the national figure for the prevalence of bleeding gums for the same age group is $46.3 \%$ [14]. Similarly high caries levels have been reported in some other countries in Asia and Africa [15-17]. However, in developed countries the prevalence of dental diseases is not as high as in developing countries. For example, in the USA it has been demonstrated that the prevalence of dental caries among 12-60 month old children is $28 \%$ [18], and in Brisbane, Australia among 4-6 year olds caries prevalence is $33.7 \%$ [19].

Oral diseases are of multi-factorial etiology. The important role of socio-behavioural and environmental factors in oral health and oral diseases has been shown in many different epidemiological surveys [1]. FisherOwens and colleagues [20] have shown the importance of assessing the influences of socio-behavioural and environmental factors on oral health. Moreover, the influence of these factors on OHQoL in childhood and old age differs across settings [21-23]. In Sri Lanka, some studies have focused on the influence of demographic and socio-economic factors on the oral health of children [24-27]. These studies have looked at a broad range of factors affecting caries prevalence, the utilization of dental services and perceptions of oral health among different age groups, including preschoolers. Findings from these studies suggest that birth rank, family size, gender and income of the family are important determinants of various aspects of oral health. However, evidence of the effect of demographic and socio-economic factors on OHQoL of the pre-school age is lacking.

The aim of the present study was to assess the effect of selected socio-demographic factors on dental caries, gingival bleeding and OHQoL in preschool children in the Kegalle district in Sri Lanka. It was hypothesized that there are ethnic differentials in oral health and OHQoL and that children from disadvantaged families have poorer oral health outcomes, as measured by dental caries, gingival bleeding and OHQoL. Ethnic and socio-economic differences in oral health outcomes and OHQoL are reported and the possible explanations are discussed.

\section{Methods}

This study was carried out among 48-72 month-old preschool children in the Kegalle district of Sri Lanka, which has an agricultural economy with a population of almost 780,000 people [28]. The study used a cross-sectional design and a formula for estimating a population proportion with absolute precision was used to calculate the sample size. Considering $65 \%$ as the prevalence estimate of caries in 6 year olds [14], at a 95\% confidence interval the calculated minimum sample size was 350 . Making allowances for a $2 \%$ design effect and a $15 \%$ non-response rate, the required sample size was 805 . Initially 838 subjects were enrolled in the study, which exceeded the required sample size. None of the parents refused to take part in the study and all answered the questionnaires. Furthermore, no handicapped children were encountered, who would have been excluded. However, the final analysis included only 784 subjects who completed oral examinations, giving a response rate of $94 \%$.

The study sample was selected using the cluster sampling technique. A preschool was considered as a cluster. Since more clusters with fewer individuals would reduce the cluster effect [29], it was decided to include 84 clusters with ten children in each. For administrative purposes, Kegalle District is divided in to 11 Divisional Secretariat Divisions (DSDs). Based on the preschool population in each DSD, the number of clusters to select from each DSD was determined according to the probability proportionate to size technique. The minimum number of clusters selected in a DSD was 4, and the maximum was 14, according to their preschool population.

According to the following steps the required number of preschools (clusters) was identified in each DSD. The main commercial location of the area was identified. The closest preschool was selected as the first cluster from that area. The preschool closest to the first in a randomly selected direction was selected as the second cluster. This method was followed until the required number of clusters was identified from each DSD. If a selected preschool had more than ten eligible children, ten children were selected by drawing lots. If a selected preschool did not have ten eligible children, the remaining number was selected from the next nearest preschool.

OHQoL was assessed by the Early Childhood Oral Health Impact Scale (ECOHIS) [2], which measures the impact of oral health problems of the preschool child on the quality of life of the child as well as his/her family. ECOHIS includes nine items related to the child and four items to the family. Calculation of ECOHIS scores was done according to the method suggested by the authors of the scale. A "do not know" response was considered as a missing response. Cases with more than 2 missing responses in Section 1 the child, and more than one missing response in Section 2 the family, were excluded 
from the relevant sections during the analysis. If any respondent had only 1 or 2 missing responses for the child section and 1 missing response for the family section, for those responses, a value was given by averaging the score of the other questions answered.

Guidance of a communication specialist was obtained in order to refine the language of ECOHIS for better clarity and comprehension. The face validity and content validity of the translated questionnaire were assessed by a consultant in Community Medicine. Consensual validity of the questionnaire was ensured by considering the comments of two experts in public health. The construct validity of the questionnaire was assessed by administering it to a group of mothers of preschool children and by determining the associations between the quality of life scores in the child and family sections and the parent's/caregiver's rating of the child's oral health. The internal consistency of the questionnaire was assessed using Cronbach's alpha. The Cronbach's alpha for the child section was 0.93 and for the family section 0.91 , indicating good internal consistency.

ECOHIS was validated in the Sinhalese language. However each time the questionnaire was applied to a member of the Tamil ethnic group, a Tamil translation of the questionnaire prepared by an expert in both languages was used to explain the questions to the respondent by the preschool teacher who served as an interpreter.

Data were collected by means of self-administered questionnaires to each parent/caregiver and an oral examination of the child. Assistance in answering the questionnaires was provided by a trained person for those who had difficulty in understanding the contents. Dental caries and gingival bleeding were assessed by the first author under natural daylight while the child was seated on a chair. The examiner was trained and calibrated with a specialist in paediatric dentistry on the recording of caries and gingival bleeding. Caries was recorded as the $\mathrm{dmfs}$ score according to the criteria recommended by Drury et al. [30]; noncavitated lesions, cavitated lesions, missing due to caries and filled. Gingival bleeding was assessed by running a periodontal probe along the cervical margins on 4 surfaces of 6 teeth; the distal, buccal/labial and lingual/palatal surfaces of 55, 61, 63, 75, 81 and 83, as suggested by Ramfjord [31], and the number of surfaces with bleeding was determined. Intra - examiner agreement associated with caries detection and gingival bleeding as determined by the Kappa statistic was 0.89 and 0.85 respectively, representing excellent agreement [29].

The questionnaire was pre-tested on a group of 20 mothers of preschool children who were not included in the main study. Based on the findings of the pre-test, certain questions were rephrased for better clarity. A pilot study was carried out with another group of 20 mothers and their children who were from the same area but excluded from the main study. This included the administration of the questionnaires as well as examinations of the children. The time required for administering the questionnaires and for the physical and oral examinations of a child was determined.

Stata Version 11 (Stata Corporation, College Station, TX, USA) was used for statistical analysis. Family income was reported in Sri Lankan Rupees. However, for the purpose of analysis, income and age were entered as continuous variables. Educational level of mother and father was reported in three levels, which were derived from the categorization used in the Demographic and Health Survey Sri Lanka 2006/7 [32]. Since very few respondents had no schooling, both "no education" and "primary education" were categorised as " $\leq 5$ grade". "Secondary education" and "passed GCE O/L (up to GCE A/L)" were included in the category "6-12 grade". Those who had attained more than GCE A/L (higher) were categorized in the " $>12$ grade" (diploma/degree or tertiary education).

Since our dependent variables were count data, adjusted robust Poisson regression bivariate and multivariate models were performed to obtain the incidence rate ratio (and its 95\% confidence intervals) and to determine factors associated with poor oral health (dental caries and gingival bleeding) and OHQoL. We used the vce (robust) option in STATA to obtain robust standard errors for the parameter estimates and to control for mild violation of underlying assumptions [33]. Significance was retained at $\mathrm{P}<0.05$.

The study was approved by the Ethics Review Committee, Faculty of Medicine, University of Colombo, Sri Lanka. Written informed consent of the parents/caregivers was also obtained.

\section{Results}

The demographic characteristics of the sample and oral health outcomes are presented in Tables 1 and 2 respectively. A total of 838 parent-child pairs were invited to take part in the study, but only 784 children took part in the oral examinations, giving a response rate of $94 \%$.

In the unadjusted analyses, high caries levels were associated with Tamil ethnicity, lower household income and low educational level of father and mother, while higher gingival bleeding levels were associated with older age, being a boy, belonging to Muslim and Tamil ethnic groups, low household income level and grade 5 or lower level of education of mother (Table 3). Poor OHQoL among children was associated with older age, Muslim and Tamil ethnicities and lower levels of father's and mother's education. Lower OHQoL of family was associated with Muslim ethnicity, mother's education (grade 6-12) and father's education (grade 6-12) (Table 4).

Multivariate analysis showed that caries was significantly higher in children whose fathers had $\leq 5$ years of education 
Table 1 Distribution of sample according to selected socio-demographic variables

\begin{tabular}{|c|c|c|}
\hline Variable & $\mathrm{n}$ & $\%$ \\
\hline Total & 784 & 100 \\
\hline \multicolumn{3}{|l|}{ Age } \\
\hline $48-60$ months & 466 & 59.4 \\
\hline $61-72$ months & 318 & 40.6 \\
\hline Mean age (SD) & 57.30 & $(6.24)$ \\
\hline \multicolumn{3}{|l|}{ Gender } \\
\hline Boys & 383 & 48.9 \\
\hline Girls & 401 & 51.1 \\
\hline \multicolumn{3}{|l|}{ Ethnicity } \\
\hline Sinhala & 704 & 89.8 \\
\hline Muslim & 62 & 7.9 \\
\hline Tamil & 18 & 2.3 \\
\hline \multicolumn{3}{|c|}{ Family income (Sri Lankan Rupees) } \\
\hline$<10,000$ & 416 & 53.6 \\
\hline $10,001-20,000$ & 221 & 28.5 \\
\hline 20,001 and above & 138 & 17.8 \\
\hline non-response & 9 & \\
\hline Mean income (SD) & 14967.03 & $(10449.24)$ \\
\hline \multicolumn{3}{|l|}{ Education level of mother } \\
\hline$\leq$ grade 5 & 35 & 4.5 \\
\hline grade $6-12$ & 636 & 81.5 \\
\hline$>$ grade 12 (degree/diploma) & 109 & 14.0 \\
\hline non-response & 4 & \\
\hline \multicolumn{3}{|l|}{ Education level of/ father } \\
\hline$\leq$ grade 5 & 52 & 6.7 \\
\hline grade $6-12$ & 656 & 84.1 \\
\hline$>$ grade 12 (degree/diploma) & 72 & 9.2 \\
\hline non-response & 4 & \\
\hline
\end{tabular}

Non-respondents were excluded when calculating the percentages.

compared to those whose fathers had $>12$ years of education (IRR $=2.30 ; 95 \%$ CI: 1.30, 4.06; $\mathrm{p}<0.01$ ) while gingival bleeding was significantly higher in Tamil children (IRR = 3.04; 95\% CI: 1.92, 4.81; $\mathrm{p}<0.001)$ compared to Sinhala children and in children of low income earners compared to children of higher income earners (IRR $=1.00$; 95\% CI:0.99,1.00; $\mathrm{p}<0.05$ ) (Table 3). Poor OHQoL in children as measured by ECOHIS child scores was associated with Tamil ethnicity (IRR $=2.07 ; 95 \% \mathrm{CI}: 1.19,3.60 ; \mathrm{p}<0.01$ ) and low level of education of father ( $\leq$ grade 5 : IRR $=2.52$; 95\% CI: 1.20, 5.31; p <0.05) (Table 4). However, children whose mothers had $\leq 5$ years of education had lower ECOHIS scores, hence better OHQoL than those whose mothers had $>12$ years of education (IRR $=0.31$; $95 \%$ CI:0.15,0.64; $\mathrm{p}<0.001$ ). Higher ECOHIS family scores (i.e. poor OHQoL at family level) were associated with Muslim
Table 2 Distribution of sample according to oral Health outcomes and oral Health-related Quality of Life

\begin{tabular}{lll}
\hline Variable & $\mathbf{n}$ & \% \\
\hline Total & 784 & 100 \\
Dental caries & & \\
$\quad$ caries present & 564 & 71.9 \\
$\quad$ caries absent & 220 & 28.1 \\
$\quad$ Mean (SD) dmfs & $6.4(8.5)$ & \\
Gingival bleeding & & \\
$\quad$ bleeding present & 369 & 47.1 \\
$\quad$ bleeding absent & 415 & 52.9 \\
$\quad$ Mean (SD) bleeding surfaces & $1.1(1.5)$ & \\
Oral health-related quality of life & & 42.5 \\
$\quad$ children affected & 332 & 57.5 \\
children not affected & 449 & \\
$\quad$ non-response & 3 & 21.0 \\
$\quad$ Mean (SD) ECOHIS child score & $2.2(3.6)$ & 79.0 \\
families affected & 164 & \\
families not affected & 617 & \\
non-response & 3 & \\
Mean (SD) ECOHIS family score & $0.6(1.5)$ & \\
\hline Non-respondents were excluded when calculating the percentages. &
\end{tabular}

ethnicity $(\mathrm{IRR}=1.42 ; 95 \% \mathrm{CI}: 1.10,1.84 ; \mathrm{p}<0.01)$ and lower levels of education of fathers ( $>$ grade 12: IRR $=1.37$; 95\% CI: 1.11, 1.69; $\mathrm{p}<0.01$ ) ( $\leq$ grade 5 : IRR $=1.59 ; 95 \%$ CI: 1.11, 2.27; $\mathrm{p}<0.05)$ (Table 4).

\section{Discussion}

The prevalence of dental caries among children in the present study $(72 \%)$ is comparable to the prevalence rates reported for children of similar ages from neighbouring and other low- and middle-income countries. For example, Hashim et al. examined dental caries experience and use of dental services among preschool children in Ajman, United Arab Emirates. They found that the prevalence of dental caries among preschool children was $76.1 \%$, [34], while $62 \%$ of 3-5 year olds from Uganda had dental caries [19]. In the present study, bleeding gums were present in $47 \%$ of the sample. In Bangladesh it was found that gingival bleeding was present among $67 \%$ of children aged between $5-15$ years [35].

Although in our adjusted model we found that the association between mother's education and caries levels disappeared, higher caries levels were associated with low educational attainment of the father (Table 3). Moreover, Hashim et al. have shown that poor child oral health is associated with low educational attainment among mothers [34]. Similar findings with regard to the association between poor oral health of the child and parental education have been observed in several other studies. For 
Table 3 Associations between selected socio-demographic variables and oral health outcomes (caries and bleeding gums)

\begin{tabular}{|c|c|c|c|c|c|c|c|c|}
\hline \multirow[t]{2}{*}{ Variables } & \multicolumn{4}{|c|}{ Caries ( dmfs) } & \multicolumn{4}{|c|}{ Bleeding gums (bleeding surfaces) } \\
\hline & $\begin{array}{l}\text { Unadjusted } \\
\text { coefficient (SE) }\end{array}$ & IRR (95\% Cl) & $\begin{array}{c}\text { Adjusted } \\
\text { coefficient (SE) }\end{array}$ & IRR $(95 \% \mathrm{CI})$ & $\begin{array}{l}\text { Unadjusted } \\
\text { coefficient (SE) }\end{array}$ & IRR $(95 \% \mathrm{Cl})$ & $\begin{array}{c}\text { Adjusted } \\
\text { coefficient (SE) }\end{array}$ & IRR (95\% Cl) \\
\hline Age & $0.01(0.01)$ & $1.01(0.99,1.03)$ & $-0.00(0.01)$ & $0.99(0.98,1.01)$ & $0.02^{*}(0.01)$ & $1.02^{*}(1.00,1.04)$ & $0.02(0.01)$ & $1.02(1.00,1.04)$ \\
\hline \multicolumn{9}{|l|}{ Gender } \\
\hline Boys & $0.13(0.09)$ & $1.14(0.95,1.38)$ & $0.14(0.09)$ & $1.15(0.95,1.39)$ & $-0.21^{*}(0.10)$ & $0.81^{*}(0.67,0.99)$ & $-0.18(0.10)$ & $0.83(0.68,1.01)$ \\
\hline \multicolumn{9}{|l|}{ Ethnicity } \\
\hline Muslim & $0.26(0.14)$ & $1.30(0.98,1.71)$ & $0.25(0.14)$ & $1.28(0.98,1.68)$ & $0.45^{* *}(0.15)$ & $1.57^{* *}(1.15,2.12)$ & $0.29(0.15)$ & $1.34(0.99,1.81)$ \\
\hline Tamil & $0.68^{* * *}(0.21)$ & $1.97^{* * *}(1.30,3.00)$ & $0.51(0.27)$ & $1.66(0.98,2.81)$ & $0.95^{* * *}(0.25)$ & $2.58^{* * *}(1.59,4.21)$ & $1.11^{* * *}(0.23)$ & $3.04^{* * *}(1.92,4.81)$ \\
\hline Income (SL Rupees) & $-0.00^{* * *}(5.11)$ & $1.00^{* * *}(1.00,0.99)$ & $-7.91(5.00)$ & $1.00(0.99,1.00)$ & $-0.00^{* * *}(5.19)$ & $1.00^{* * *}(0.99,1.00)$ & $-0.00^{*}(5.17)$ & $1.00^{*}(0.99,1.00)$ \\
\hline \multicolumn{9}{|l|}{ Father's education } \\
\hline Grade 6-12 & $0.59^{* *}(0.23)$ & $1.80^{* *}(1.15,2.83)$ & $0.28(0.24)$ & $1.33(0.83,2.13)$ & $0.16(0.23)$ & $1.18(0.75,1.85)$ & $(0.01)(0.32)$ & $1.01(0.55,1.89)$ \\
\hline Grade $\leq 5$ & $1.02^{* * *}(0.27)$ & $2.77^{* * *}(1.64,4.67)$ & $0.83^{* *}(0.29)$ & $2.30^{* *}(1.30,4.06)$ & $0.47(0.27)$ & $1.60(0.94,2.72)$ & $0.07(0.36)$ & $1.08(0.53,1.20)$ \\
\hline \multicolumn{9}{|l|}{ Mother's education } \\
\hline Grade 6-12 & $0.40^{* *}(0.14)$ & $1.49^{* *}(1.12,1.98)$ & $0.18(0.15)$ & $1.19(0.89,1.61)$ & $-0.05(0.16)$ & $0.95(0.69,1.30)$ & $-0.19(0.23)$ & $0.83(0.52,1.31)$ \\
\hline Grade $\leq 5$ & $0.45(0.24)$ & $1.57(0.98,2.51)$ & $-0.26(0.27)$ & $0.77(0.45,1.30)$ & $0.52^{*}(0.23)$ & $1.69^{*}(1.07,2.67)$ & $0.19(0.30)$ & $1.21(0.67,2.19)$ \\
\hline
\end{tabular}

${ }^{*} \mathrm{p}<0.05^{* * *} \mathrm{p}<0.01{ }^{* * *} \mathrm{p}<0.001$

IRR = Incidence Rate Ratio $\mathrm{SE}=$ Standard Error $95 \% \mathrm{Cl}=95 \%$ Confidence Interval.

Reference categories: Gender- girls, Ethnicity- Sinhalese, Father's and Mother's education- > grade 12 
Table 4 Associations between selected socio-demographic variables and oral health-related quality of life

\begin{tabular}{|c|c|c|c|c|c|c|c|c|}
\hline \multirow[t]{2}{*}{ Variables } & \multicolumn{4}{|c|}{ ECOHIS score (child) } & \multicolumn{4}{|c|}{ ECOHIS score (family) } \\
\hline & $\begin{array}{l}\text { Unadjusted } \\
\text { coefficient (SE) }\end{array}$ & IRR (95\% Cl) & $\begin{array}{c}\text { Adjusted } \\
\text { coefficient (SE) }\end{array}$ & IRR (95\% Cl) & $\begin{array}{l}\text { Unadjusted } \\
\text { coefficient (SE) }\end{array}$ & IRR $(95 \% \mathrm{Cl})$ & $\begin{array}{c}\text { Adjusted } \\
\text { coefficients (SE) }\end{array}$ & IRR $(95 \% \mathrm{Cl})$ \\
\hline Age & $0.02^{*}(0.01)$ & $1.02^{*}(1.00,1.05)$ & $0.02(0.01)$ & $1.02(0.99,1.04)$ & $0.00(0.00)$ & $1.00(0.99,1.01)$ & $0.00(0.00)$ & $1.00(0.99,1.01)$ \\
\hline \multicolumn{9}{|l|}{ Gender } \\
\hline Boys & $0.06(0.12)$ & $1.06(0.84,1.34)$ & $0.12(0.12)$ & $1.13(0.89,1.43)$ & $0.00(0.06)$ & $1.00(0.88,1.13)$ & $0.03(0.07)$ & $1.03(0.91,1.18)$ \\
\hline \multicolumn{9}{|l|}{ Ethnicity } \\
\hline Muslim & $0.43^{*}(0.21)$ & $1.54^{*}(1.02,2.32)$ & $0.37(0.22)$ & $1.45(0.95,2.23)$ & $0.41^{* * *}(0.12)$ & $1.51^{* * *}(1.18,1.92)$ & $0.35^{* *}(0.13)$ & $1.42^{* *}(1.10,1.84)$ \\
\hline Tamil & $0.76^{* * *}(0.23)$ & $2.15^{* * *}(1.36,3.40)$ & $0.73^{* *}(0.28)$ & $2.07^{* *}(1.19,3.60)$ & $0.12(0.18)$ & $1.13(0.79,1.61)$ & $-0.14(0.15)$ & $0.87(0.65,1.17)$ \\
\hline \multicolumn{9}{|l|}{ Income } \\
\hline (SL Rupees) & $-7.49(6.05)$ & $1.00(0.99,1.00)$ & $4.47(6.16)$ & $1.00(0.99,1.00)$ & $-1.10(3.15)$ & $1.00(0.99,1.00)$ & $4.82(3.26)$ & $1.00(0.99,1.00)$ \\
\hline \multicolumn{9}{|c|}{ Father's education } \\
\hline Grade 6-12 & $0.71^{* *}(0.25)$ & $2.04^{* *}(1.25,3.34)$ & $0.53(0.29)$ & $1.69(0.96,2.98)$ & $0.37^{* * *}(0.06)$ & $1.45^{* * *}(1.29,1.63)$ & $0.31^{* *}(0.11)$ & $1.37^{* *}(1.11,1.69)$ \\
\hline Grade $\leq 5$ & $0.77^{*}(0.32)$ & $2.15^{*}(1.15,4.05)$ & $0.92^{*}(0.38)$ & $2.52^{*}(1.20,5.31)$ & $0.35^{* *}(0.13)$ & $1.42^{* *}(1.10,1.82)$ & $0.46^{*}(0.18)$ & $1.59^{*}(1.11,2.27)$ \\
\hline \multicolumn{9}{|c|}{ Mother's education } \\
\hline Grade 6-12 & $0.38^{*}(0.18)$ & $1.46^{*}(1.02,2.07)$ & $0.13(0.20)$ & $1.14(0.77,1.68)$ & $0.21^{*}(0.08)$ & $1.23^{*}(1.04,1.45)$ & $0.15(0.11)$ & $1.16(0.94,1.43)$ \\
\hline Grade $\leq 5$ & $0.01(0.44)$ & $1.01(0.43,2.38)$ & $-1.16^{* * *}(0.36)$ & $0.31^{* * *}(0.15,0.64)$ & $0.13(0.19)$ & $1.14(0.79,1.65)$ & $-0.31(0.16)$ & $0.74(0.53,1.02)$ \\
\hline
\end{tabular}

${ }^{*}<<0.05{ }^{* *} \mathrm{p}<0.01{ }^{* * *} \mathrm{p}<0.001$.
$\mathrm{IRR}=$ Incidence Rate Ratio $\mathrm{SE}=$ Standard Error $95 \% \mathrm{Cl}=95 \%$ Confidence Interval.

$\mathrm{IRR}=$ Incidence Rate Ratio $\mathrm{SE}=\mathrm{Standard}$ Error $95 \% \mathrm{Cl}=95 \%$ Confidence Interval.
Reference categories: Gender- girls, Ethnicity- Sinhalese, Father's and Mother's education- > grade 12. 
example, having reviewed findings from several national surveys of children between 2-4 years and 6-8 years, Edelstein reported that children of parents with less than high school education had the highest caries experience compared to children of parents with higher education levels [36]. In another study carried out among Brazilian preschool children, it was found that children who had parents with $<8$ years of education experienced higher levels of caries than the children of more educated parents [37]. However, contrary to these findings, Schroth et al. found that caregiver's education was not associated with early childhood caries (ECC) [38], and the authors attributed their finding to the more equal levels of education of the care- givers who participated in that study.

We have found that higher bleeding tendencies are associated with lower income levels (Table 3). Similar findings have been demonstrated in research indicating that low family income is associated with poor oral health outcomes of children. For example, Finlayson et al. found that children under 6 years of age of low income families are more prone to caries [39]. In a study done among Brazilian preschool children, Piovesan et al. found that children of families with low household incomes had higher caries levels than the children of families with higher incomes [40].

Furthermore, we found that higher bleeding tendencies are associated with the Tamil ethnic group (Table 3). This finding demonstrates the existence of ethnic differentials in oral health outcomes. Hashim et al. also found that Emirati children have poorer oral health than children of other ethnicities [34]. Similarly Piovesan et al. found that non-white children have higher caries levels than white children [40]. Tinanoff and Reisine indicate that ethnic minority groups experience poor oral health outcomes due to various factors, such as how health care providers interact with them, accessibility to resources, level of patient's trust and patient perceptions about the etiology, course and outcomes of disease [41].

The OHQoL of the child is significantly associated with Tamil ethnicity, and low levels of education of the father ( $\leq$ grade 5) (Table 4). Piovesan et al. found that low household income is a risk factor for poor OHQoL in children ( $R R=$ 1.13) [42]. This finding explains our finding of an association of low education of the father with lower OHQoL of the child. Obviously, if the father of the family has a low education level, the income of the family is reduced.

Piovesan et al. state that children of mothers with low education experience poorer OHQoL $(R R=1.3)$ [42]. In contrast, our research found that low educational attainment among mothers was associated with better OHQoL. This significant negative association was observed in the lowest ( $\leq$ grade 5 ) education category. Low education level may lead to unemployment [42], which is consistent with our data that show $>94 \%$ unemployment in the above group. It has been found that children whose mothers are employed are more likely to consume sweetened beverages and less likely to consume fruit and vegetables between meals [43]. Obviously, this may lead to poor oral health and poor OHQoL of the children. Moreover, unemployed mothers have more time to observe and guide their children in tooth brushing, to take their children to government dental clinics which provide free services, and to participate in free workshops and public health events that provide current oral health knowledge than their employed counterparts.

Poor OHQoL of the family is significantly associated with Muslim ethnicity and lowest level of father's education ( $\leq$ grade 5) (Table 4). According to our demographic data, compared to Sinhala families, in Muslim families there is a relatively large number of siblings. With this high number, the attention given to each child and other family members may not be adequate. Oral health is no an exception to this phenomenon. We also found that $32 \%$ of the Muslim families belonged to the lowest income level, whereas only $13 \%$ of Sinhala families belonged in that category. Therefore, as a result of increased family size and lower economic level, oral health-related quality of life of the family may deteriorate. A study carried out in Sri Lanka has demonstrated consistent results, and the authors indicate that children who had $\geq 2$ siblings had significantly more caries than children of families with $\leq 2$ siblings [27]. On the other hand, the lower education level of the father may adversely affect OHQoL of the family, for the reasons mentioned in the previous paragraph.

Comparable studies undertaken in countries with very disadvantaged population sub-groups have also demonstrated similar results with regard to oral health outcomes such as dental caries and gingival bleeding $[17,34,35]$. Hence, there is the possibility of generalizing of our findings to other areas in Sri Lanka and other countries, especially those with similar socioeconomic backgrounds.

There are some methodological limitations of this study. For example, there may have been situations where the respondents were reluctant to divulge information. When administering the questionnaires to Tamil speaking respondents, the assistance of a competent interpreter was obtained. However, it is possible that certain questions may have been misinterpreted.

\section{Conclusions}

Father's education is an important factor in determining dental caries and OHQoL among preschool children. Members of ethnic minorities carry the greatest burden of poor oral health outcomes, with Tamils having the highest level of bleeding gums and poorest child OHQoL and Muslims having the poorest OHQoL at the family level. Therefore, father's education level and ethnicity are the key dimensions to consider when planning and providing oral health services to preschool children in this area. 


\section{Abbreviations}

Dmfs: Decayed missing and filled surfaces; DSD: Divisional secretariat division; ECC: Early childhood caries; ECOHIS: Early childhood oral health impact scale; OHQoL: Oral health-related quality of life.

\section{Competing interests}

The authors declare that they have no competing interests.

\section{Authors' contributions}

VN and LE designed the study. Data collection, including oral examination of the children and administering the questionnaires, was done by VN. AR did the data analysis. All authors were involved in interpreting the data, while VN and LE drafted the manuscript. AR and BO revised the draft critically. All authors have given their consent to the final draft.

\section{Authors' information}

VN (BDS, MSc) - Visiting Academic, Global Health and Society Unit, Monash University; Senior Registrar (Community Dentistry), Ministry of Healthcare and Nutrition, Sri Lanka.

AR (PhD, MPH, MPHAA) - ARC Future Fellow and Director Migration, Social Disadvantage, and Health Programs, Department of Epidemiology \& Preventive Medicine, Monash University; Senior Fellow- Nutrition, Centre for International Health, Burnet Institute.

BO- (PhD) - Professor of International Public Health; Associate Dean (Global Health and International Campuses), Monash University; Director, Global Health and Society Unit, Monash University.

LE (BDS, PhD) - Professor in Community Dentistry, Department of Community Dental Health, Faculty of Dental Sciences, University of Peradeniya, Sri Lanka.

\section{Acknowledgement}

The study was supported by a grant from the Education, Training and Research unit of the Ministry of Healthcare and Nutrition, Sri Lanka.

\section{Author details}

${ }^{1}$ Global Health and Society Unit, Department of Epidemiology and Preventive Medicine, Monash University, Level 3, Burnet Building, 89 Commercial Rd, Melbourne, Victoria 3004, Australia. ${ }^{2}$ Ministry of Healthcare and Nutrition, Colombo, Sri Lanka. ${ }^{3}$ Global Health and Society Unit, Monash University; Burnet Institute, Level 3, Burnet Building, 89 Commercial Rd, Melbourne, Victoria 3004, Australia. ${ }^{4}$ Department of Community Dental Health, Faculty of Dental Sciences, University of Peradeniya, Peradeniya, Sri Lanka.

Received: 6 June 2013 Accepted: 6 November 2013

Published: 14 November 2013

\section{References}

1. Petersen PE, Bourgeois D, Ogawa H, Estupinan-Day S, Ndiaye C: The global burden of oral diseases and risks to oral health. Bull World Health Organ 2005, 83:661-669.

2. Pahel B, Rozier RG, Slade G: Parental perceptions of children's oral health The Early Childhood Oral Health Impact Scale (ECOHIS). Health Qual Life Outcomes 2007, 5(Suppl1):6.

3. Rayner J, Holt R, Blinkhorn F, Duncan K: A policy document on oral health care in preschool children. Int J Paediatr Dent 2003, 13:279-285.

4. Kowash MB, Pinfield A, Smith J, Curzon MEJ: Effectiveness on oral health of a long-term health education programme for mothers with young children. Br Dent J 2000, 188:201-205.

5. Rayner JA: A dental health education programme, including home visits, for nursery school children. Br Dent J 1992, 172:57-62

6. Levin KA, Davies CA, Topping GVA, Assaf AV, Pitts AB: Inequalities in dental caries of 5-year- old children in Scotland, 1993-2003. Eur J Publ Health 2009, 19(Suppl 3):337-342.

7. Pattussi MP, Marcenes W, Croucher R, Sheiham A: Social deprivation, income inequality, social cohesion and dental caries in Brazilian school children. Soc Sci Med 2001, 53(Suppl 7):915-925.

8. Shiboski CH, Gransky SA, Ramos-Gomez F, Ngo L, Isman R, Pollick HF: The Association of Early Childhood Caries and Race/Ethnicity among California preschool children. J Public Health Dent 2003, 63(Suppl 1):38-46.
9. Christensen LBT, Twetman S, Sundby A: Oral Health in children and adolescents with different socio-cultural and socio-econimic backgrounds. Acta Odontol Scand 2010, 68:34-42.

10. Hallett KB, O'Rourke PK: Social and behavioural determinents of early childhood caries. Aust Dent J 2003, 48(Suppl 1):27-33.

11. Waxman A: Prevention of chronic diseases: global strategy on diet, physical activity and health. Food Nutr Bull 2003, 24(Suppl 3):281-284

12. Ministry of Health Sri Lanka: National Oral Health Survey 2003/2004. Colombo: Ministry of Health; 2007.

13. Watt RG: From victim blaming to upstream action: tackling the social determinants of oral health inequalities. Community Dent Oral Epidemiol 2007, 35(Suppl 1):1-11.

14. Ministry of Health Sri Lanka: National Oral Health Survey 1993/1994. Colombo: Ministry of Health; 1998

15. Carino KMG, Shinada K, Kawaguchi Y: Early childhood caries in Nothern Phillippines. Community Dent Oral Epidemiol 2003, 31:81-89.

16. Jin B, Ma D, Moon H, Paik D, Hahn S, Horowitz AM: Early childhood caries: prevalence and risk factors in Seoul Korea. J Public Health Dent 2003 63(Suppl 3):183-188.

17. Kiwanuka SN, Astron AN, Trovik TA: Dental caries experience and its relationship to social and behavioural factors among 3-5 year old children in Uganda. Int J Paediatr Dent 2004, 14(Suppl 5):336-346.

18. Kopycka-Kedzierawski DT, Billings RJ: Prevalence of dental caries and dental care utilization in preschool urban children enrolled in a comparativeeffectiveness study. Eur Arch Paediatr Dent 2011, 12(suppl 3):133-138.

19. Hallet KB, O'Rourke PK: Dental caries experience of preschool children from the North Brisbane region. Aust Dent J 2002, 47(suppl 4):331-338.

20. Fisher-Owens SA, Gansky SA, Platt $\sqcup$, Weintraub JA, Soobader MJ, Bramlett MD Newacheck PW: Influences on children's oral health: a conceptual model. Pediatriacs 2007, 120(Suppl 3):510-520.

21. Low W, Tans S, Schwartz S: The effect of severe caries on the quality life in young children. Pediatr Dent 1999, 21(Suppl 6):325-326.

22. Global burden of disease. http://www.fdiworldental.org.

23. Mignogna MD, Fedel S: The neglected global burden of chronic oral diseases. J Dent Res 2006, 85(Suppl 5):390-391.

24. Amaratunge A, Heidmann J, Jayatilake $K$ : Oral health in a group of pre-school children attending dental nurse clinics in the Kandy area, Sri Lanka. Community Dent Health 1986, 3(Suppl 2):169-174.

25. Ekanayake L, Ando $Y$, Miyazaki H: Patterns and factors affecting Dental utilization among adolescents in Sri Lanka. Int Dent J 2001, 51(5):353-358

26. Perera I, Ekanayake L: Factors influencing perception of oral health among adolescents in Sri Lanka. Int Dent J 2008, 58(6):349-355.

27. Wellappuli N, Amarasena N: Influnce of family structure on dental caries experience of preschool children in Sri Lanka. Caries Res 2012, 46:208-212.

28. Department of Census and Statistics Sri Lanka: District report - Kegalle district. Colombo: Department of Census and Statistics; 2001

29. Abrahamson $\mathrm{JH}$, Abrahamson ZH: Survey Methods in Community Medicine: Epidemiological Research, Programme Evaluation, Clinical trials. Edinburgh: Churchill Livingstone; 1999.

30. Drury TF, Horowitz AM, Ismail Al, Maertens MP, Rozier RG, Selwitz RH: Diagnosing and reporting early childhood caries for research purposes. J Public Health Dent 1999, 59(3):192-197.

31. Ramfjord SP: Indices for prevalence and incidence of periodontal disease. J Periodontol 1959, 30:51-59.

32. Department of Census and Statistics Sri Lanka: Demographic and Health Survey 2006-07. Colombo: Department of Census and Statistics; 2009.

33. Cameron AC, Trivedi PK: Microeconometrics using stata. The Stata News 2008, 23(Number 4):688.

34. Hashim R, Thomson WM, Ayers KMS, Lewsey JD, Awad M: Dental caries experience and use of dental services among preschool children in Ajman, UAE. Int J Paediatr Dent 2006, 16(4):257-262.

35. Sarwar AFM, Kabir MH, Rahman AFMM, Haque M, Kasem MA, Ahmad SA, Debnath PK, Mallic PC, Hque M, Hossain KA, Khan S, Ahmed AHHU, Parveen S: Oral hygiene practice among the primary school children in selected rural areas of Bangladesh. Journal of Dhaka National Medical College \& Hospital 2011, 18(Issue 1):43-48.

36. Edelstein BL: Disparities in oral health and access to care: findings of national surveys. Ambul Pediatr 2002, 2(2):141-147. 
37. Oliveira LB, Sheiham A, Bonecker M: Exploring the association of dental caries with social factors and nutritional status in Brazilian preschool children. Eur J Oral Sci 2008, 116(1):37-43.

38. Schroth RJ, Moor P, Brothwell DJ: Prevalence of early childhood caries in 4 Manitoba communities. Journal of Canadian Dental Association 2005, 71(No 8):567.

39. Finlayson TL, Siefert K, Ismail Al, Sohn W: Psychosocial factors and early childhood caries among low income African-American children in Detroit. Community Dent Oral Epidemiol 2007, 35(6):439-448.

40. Piovesan C, Mendes FM, Ferreira FV, Guedes RS, Ardenghi TM: Socio-economic inequalities in the distribution of dental caries in Brazilian preschool children. J Public Health Dent 2010, 70(4):319-326.

41. Tinanoff $\mathrm{N}$, Reisine $\mathrm{S}$ : Update on early childhood caries since the surgeon general's report. Acad Pediatr 2009, 9(6):396-403.

42. Piovesan C, Antunes JLF, Guedes RS, Ardenghi TM: Impact of socio-economic and clinical factors on child oral health-related quality of life (COHRQoL). Qual Life Res 2010, 19:1359-1366.

43. Hawkins SS, Cole TJ, Law C: Examining the relationship between maternal employment and health behaviours in 5-year-old British children. J Epidemiol Community Health 2009, 63(Issue 12):999-1004.

doi:10.1186/1475-9276-12-89

Cite this article as: Nanayakkara et al.: Ethnic and socio-economic disparities in oral health outcomes and quality of life among Sri Lankan preschoolers: a cross-sectional study. International Journal for Equity in Health $201312: 89$.

\section{Submit your next manuscript to BioMed Central and take full advantage of:}

- Convenient online submission

- Thorough peer review

- No space constraints or color figure charges

- Immediate publication on acceptance

- Inclusion in PubMed, CAS, Scopus and Google Scholar

- Research which is freely available for redistribution 